\title{
Gender differences in academic achievement of children with developmental coordination disorder
}

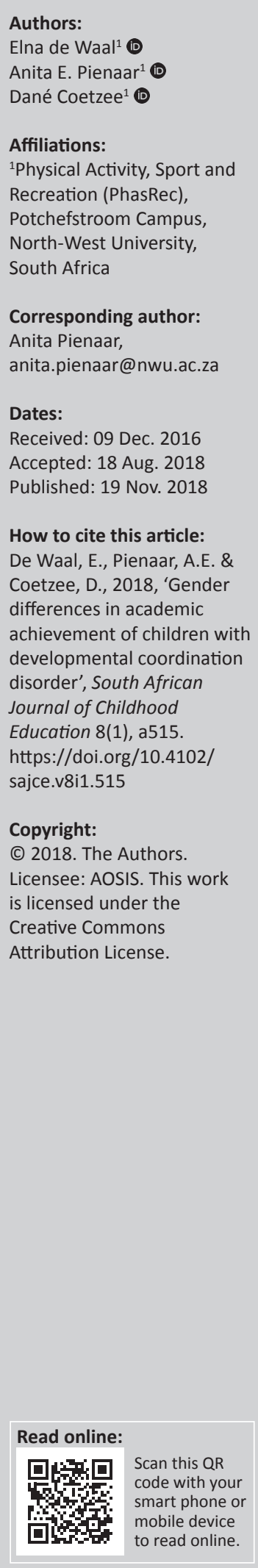

Background: Developmental coordination disorder (DCD) has a negative impact on everyday activities and academic achievement in children, mainly owing to similar underlying motor and cognitive constructs. Academic achievement of boys and girls seems to be different, with boys being more prone to academic backlogs, especially in language-related areas.

Aim: This study investigated if boys with DCD displayed more academic problems than girls with DCD.

Setting: Ten-year-old children $(N=221, \pm 0.41)$ from different economic backgrounds were randomly selected for assessment as part of the NW-CHILD (North-West Child Health, Integrated with Learning and Development) longitudinal study in the North West Province of South Africa.

Methods: The Movement Assessment Battery for Children, Second Edition, was used to determine DCD status in the group. The results of the Annual National Assessment and the mid-year June exam, which included six learning areas, were used to analyse academic differences between typically developing boys and girls and those who were identified with DCD (seven boys, seven girls). Independent $t$-testing and Mann-Whitney non-parametric tests were used to determine differences between boys and girls.

Results: Boys with DCD had inferior literacy and numeracy skills, significantly poorer manual dexterity and balancing skills and also displayed statistically and large practically significant weaker mid-year grade point averages than girls. Children with DCD also portrayed poorer academic achievement than typically developing children.

Conclusion: Significant differences in balancing skills and in languages between boys and girls with DCD might have contributed to the practically significant poorer maths performance of boys.

\section{Introduction}

The lack of motor coordination that is characteristic of children with developmental coordination disorder (DCD) contributes to poor functioning at school, home and at community level (O'Brien et al. 2008). The Diagnostic and Statistical Manual of Mental Disorders, 5th edition (DSM-5) (American Psychiatric Association 2013) describes DCD as a deficit in motor skill performance and the acquisition thereof, interfering with activities of daily living and academic achievement, in the absence of severe neurological deficits (APA 2013). DCD is more prevalent in boys according to various studies (Asonitou et al. 2012; Cheng et al. 2014; Lingam et al. 2009). A boy-girl ratio ranging from 2:1 to 7:1 have been reported by Lingam et al. (2009:698). Dewey et al. (2002:909) as well as Cairney et al. (2005:78), however, have reported no significant gender differences when using population-based samples.

Motor and cognitive development are closely intertwined and show considerable improvement between the ages of 5 and 10. The co-occurrence of motor and cognitive performance problems are furthermore coupled because these functions make use of the same brain structures (Diamond 2000; Westendorp et al. 2011). Any dysfunction in the involved brain structures can subsequently lead to motor and cognitive problems (Diamond 2000). Shared underlining processes such as sequencing (Hartman et al. 2010; Westendorp et al. 2011), monitoring and planning (Roebers \& Kauer 2009; Westendorp et al. 2011) might also contribute to this co-occurrence. Perceptual-motor problems are also reported as possible reasons for poor academic achievement (De Waal 2015; Michel et al. 2011; Nourbakhsh 2006; Pienaar, Barhorst \& Twisk 2013). In a South African study, visual perception correlated with academic achievement and served as a significant predictor for academic success (De Waal 2015), while the researcher highlighted the importance of perception 
in motor skills and especially mathematical achievement. Son and Meisels (2006:763) report in this regard that future cognitive performance is influenced by motor skills. Vuijk et al. (2011:280) furthermore report links between Mathematics and balance, dexterity and spelling, as well as reading and ball skills. According to these researchers, these findings serve as confirmation of the importance of proper perceptualmotor development for optimal academic achievement (De Waal 2015; Vuijk et al. 2011).

A number of studies confirm that learners with DCD run a higher risk of developing academic deficits compared to typically developing learners (Archibald \& Alloway 2008; Asonitou et al. 2010, 2014; Missiuna, Rivard \& Pollock 2004; Sadeghi, Abolghasemi \& Hajloo 2013). Alloway (2007:31) reports that DCD children display significant deficits in visuospatial short-term memory and working memory, which negatively influence their capacity for learning. Research by Pieters et al. (2015:92) report a significant link between DCD and semantic backlogs in Mathematics in particular. Deficits in the recalling of numerals and process calculations are also linked to DCD, where learners with moderate and serious DCD display differences in the degree of seriousness of these deficits (Pieters et al. 2012). Cheng et al. (2011:2592) furthermore report a direct relationship between DCD and writing ability in both English and Chinese learners, while only English learners experienced reading problems, possibly because English is based on an alphabetic style of writing. Various researchers (Alt, Arizmendi \& Beal 2014; Korhonen \& Linnanmäki 2012; Van Lill 2011) are also of the opinion that meticulous mathematical calculations are strongly embedded in language and are related to language skills in mathematical instructions. Children with DCD also underperform during tasks demanding a higher degree of attention and display weaker basic reading and comprehension reading skills than typically developing children (Dewey et al. 2002). Deficits such as weaker attention, social communication, spelling and reading are also confirmed by Lingam et al. (2010).

\section{Gender differences in academic achievement}

Researchers (Melhuish et al. 2008; Voyer \& Voyer 2014) report a relationship between gender and cognitive skills. Gender is highlighted in the study of Melhuish et al. (2008:1162) as one of the many contributing factors influencing Mathematics performance, although this transpired to be the weakest predictor amongst nine other predictors in the study conducted in England. Voyer and Voyer (2014:1191) furthermore emphasise in their literature study that gender differences within academic achievement are strongly influenced by various factors. The content of course material, the nationality of learners and race are highlighted as moderating factors. Literature furthermore suggests a significant relationship between socio-economic status and academic achievement (Coe et al. 2013; Pienaar et al. 2013). Piek et al. (2008:679) report in this regard that socio-economic status at school level is a significant predictor of both cognitive and fine motor skills. A large variety of ethnic groups, languages, cultures and socio-economic circumstances are present in South Africa, all of which can contribute to extremes and inequalities in the development of children (Edginton et al. 2012), therefore making research in a South African population of importance.

Differences in academic achievement are reported between boys and girls when coordination difficulties are not present (Driessen \& Van Langen 2013; Else-Quest, Hyde \& Linn 2010; Krinzinger, Wood \& Willmes 2012; Mills, Ablard \& Stumpf 1993; Robinson et al. 1996). However, limited studies specifically focus on academic differences between boys and girls with DCD. Lingam et al. (2010:1114) report that children with possible DCD of both genders display an increased risk for learning problems and that this risk is more prevalent amongst girls than amongst boys. The prevalence of DCD is reported to be higher amongst boys (Asonitou et al. 2012; Cheng et al. 2014; Lingam et al. 2009), while they are also more prone to be diagnosed with conditions such as autism, ADD/ADHD, Tourette syndrome and learning deficits (Auxter, Pyfer \& Huettig 2010). These findings may lead to the assumption that the motor and cognitive make-up of boys and girls might differ, and because of a reported link between cognitive and motor development, this difference might subsequently also contribute to gender differences in the academic achievement of learners with DCD.

From this literature it transpires that there are differences in the academic achievement of boys and girls, without DCD being taken into account. Differences in academic achievement between boys and girls with DCD are, however, less clear. Research findings also differ regarding the significance and size of these differences amongst DCD children, as well as the contributory factors that serve as role players. South African studies (Cloete, Pienaar \& Coetzee 2006; De Milander, Coetzee \& Venter 2014) confirm that DCD is also prevalent amongst South African children. The objective of this study is therefore to determine whether there are significant gender differences in academic achievement, amongst 10-year-old learners with DCD in the North West Province, that are different to those found in typically developing children.

\section{Material and methods Study design}

Grade 3 and 4 learners in the North West Province of South Africa served as the target population for this study. This study was based on a cross-sectional cohort design that was part of a stratified and randomised longitudinal study design (North-West Child Health, Integrated with Learning and Development; NW-CHILD) that covered a period of seven school years (2010-2016). The NW-CHILD study included a baseline measurement and two follow-up time point measurements during this period (2013 and 2016). In order to determine the sample for the baseline measurements in 2010 a list of schools in the North West Province was obtained 
from the Department of Basic Education, after which randomised stratification was done according to gender, school regions and school types (Quintiles 1-5) to finalise the study's population. From the list of schools in the North West Province, which is grouped into eight education districts that each represent 12 to 22 regions, each with approximately 20 schools (minimum 12, maximum 47), four school regions and 20 schools were randomly selected with regard to population density and school status. Five schools were selected from each region, where each of these schools represented the particular quintiles (Quintile 1, representing schools in poor economic areas, to Quintile 5, representing schools in good economic areas). The Department of Basic Education in each province uses a poverty classification to classify schools in different quintiles. This poverty classification is obtained from the National Census data, which includes income, dependant ratios and levels of literacy (Pauw 2005). Quintile 1-3 schools represent children from low socio-economic environments, where Quintile 1 and 2 schools are released from paying school fees, while Quintile 4 and 5 schools represent learners from higher socio-economic schools (Pauw 2005).

\section{Participants}

The research population that formed part of this study were part of the 2013 first follow-up measurements of the NWCHILD study. Boys and girls who were part of the 2010 study in their Grade 1 year were again tested during their Grade 4 year (in some cases their Grade 3 year because of retention). The learners for this study formed part of a subpopulation of the 2013 cohort, where one of the four school districts that form part of the study was randomly selected. The 221 Grade $3(n=55)$ and 4 learners $(n=166)$ were selected from the Zeerust school district. The mean age for this particular group was 10.05 years, with a standard deviation of 0.41 and minimum and maximum age values of 8.65 years and 10.64 years, respectively. One hundred and twenty-three boys (55.66\%) and 98 girls (44.34\%) were retained in the study sample. The population included learners that represented all five quintile schools (Quintile 1, $n=48$; Quintile 2, $n=44$; Quintile 3, $n=48$; Quintile 4, $n=31$; and Quintile 5, $n=50$ ). The sample also represented different racial groups: black learners $(n=196)$, white learners $(n=26)$ and other $(n=9)$. Because of the Movement Assessment Battery for Children, Second Edition (MABC-2), which was used to determine DCD in the group, all DSM-5 criteria were applied in identifying the DCD group. The exclusion criteria entailed that children with serious neurological or intellectual disability or with co-morbidities such as ADD and ADHD were to be excluded from the study. Using information obtained from the schools less than $1 \%$ of the participants met these exclusion criteria. Children were identified by means of the MABC- 2 with possible DCD $(n=47)$ when they fell below the 16th percentile. Furthermore children who fell below the 16th percentile in the MABC-2 test and experienced academic-related problems as indicated in the second DSM-5 criteria (APA 2013) were identified with DCD $(n=14)$. To apply this specific DSM-5 criterion, learners were only placed in this DCD group if they obtained less than 39\% in two or more of the six academic learning areas and fell below the 16th percentile in the MABC-2 test. Children who were considered as borderline or at risk for DCD were hence both included in the impaired coordination group (possible DCD) and only formed part of the DSM-5 DCD group if academic achievement was negatively influenced as well.

\section{Measuring instruments}

\section{Movement Assessment Battery for children, second edition}

The MABC- 2 is a test battery that focuses on the identification of limited motor function amongst children between 3 and 16 years of age (Henderson, Sugden \& Barnett 2007). This measuring instrument is aimed at three age groups, namely 3-6 years, 7-10 years and 11-16 years. For the purposes of this study, only the tests for the age band 7-10 years were used. Eight tasks were divided amongst the following subdivisions within each age group: manual dexterity, aiming and catching, and balance. The manual dexterity subtest consisted of three sub-items, while there were two aiming and catching and three balance sub-items. Each activity was demonstrated by the test facilitator, before a practice attempt and two formal test attempts took place. The respective test items of the MABC-2 were administered by trained postgraduate students in Human Movement Science, specialising in Kinderkinetics, with sufficient training and experience in the test battery. The second test attempt was only performed if the learner failed during the first attempt, or the learner did not complete the activity within the allotted time, as determined for his or her age group on the record form. It took between 20 and 40 minutes to complete the test. Each sub-item's raw score was converted to an item-standard score. These item-standard scores were then added up in order to obtain a general standard score and percentile for each subdivision. Lastly, the total test score (sum of all eight item-standard scores) was converted to an overall standard score and percentile. The higher the standard score obtained, the better the person performed. The overall percentile attained was classified according to different DCD statuses. Percentiles equal to or lower than 5 were placed in the serious DCD category; values between the 5th and 15th percentiles fell in the risk group for DCD; while any value above the 15th percentile was placed in the normal or non-DCD category. The total test score could also be used to classify learners in DCD categories, and test scores lower than or equal to 56 placed the learner in the serious DCD category. A total test score between 57 and 67 indicated a risk for DCD, while a total test score of more than 67 placed the learner in the nonDCD category. The MABC-2 is a valid test with evident criterion-related validity between the MABC-2 and test scores from similar and more narrowly focused tests. Reliable results are reported amongst children with and without motor deficits with stability reliabilities of $r=0.77$ for the manual dexterity subtest, $r=0.84$ for the aiming and catching subtest, $r=0.73$ for the balance subtest and $r=0.80$ for the total test score (Henderson et al. 2007). 


\section{Academic achievement}

Over the past 10 years, the academic achievement of South African learners has been characterised by a decline and, although improvements have been reported, the expected targets, as set by the Department of Basic Education in 2010, have still not been fully attained (ANA 2014). In 2009, the Department of Basic Education introduced an assessment model, namely the Annual National Assessment (ANA), to be written by all learners serving as a benchmark to ensure that acceptable levels of literacy and numeracy would be attained in 2014 amongst at least $60 \%$ of all learners (ANA 2014). In 2014, an ANA Mathematics average of 37\% was announced for South African Grade 4 learners (ANA 2014).

Academic mid-year progress reports of the June examination opportunity in 2013, reflecting the rating code of the six learning areas of the specific learners in Grade 3 and 4, were requested from the schools. The six learning areas, according to the Department of Basic Education's Curriculum and Assessment Policy Statements (CAPS), included Mathematics, Home Language, Second Language, Natural Sciences, Social Sciences and Life Orientation. All the official languages in South Africa (Afrikaans, English, isiNdebele, isiXhosa, isiZulu, Sepedi, Sesotho, Setswana, SiSwati, Tshivenda, Xitsonga) were included in Grade 4 language learning. 'Home language' referred to one or two languages offered at home language level (for the applicable school or district), while 'second language' referred to a language that was not a mother tongue but that was used for certain communicative functions in a society or in the classroom (CAPS 2014). Assessment guidelines for the ANA of South African learners indicated that learners are evaluated based on knowledge that had to be mastered during the first three terms of the school year, which extended from January to December. The schools' results of the ANA that took place in September 2013, which assessed the learners' language and mathematical abilities, were also made available for this research study by the North West Department of Education (2014c). Interpretation of results in percentages was described according to grading codes of the Department of Education. A ' 7 ' was allocated to outstanding achievement $(80 \%-100 \%) ; ' 6$ ' for achievement of merit $(70 \%-79 \%) ;$ ' 5 ' described significant performance $(60 \%-69 \%)$; a ' 4 ' adequate performance $(50 \%-$ $59 \%) ; ~ ' 3$ ' moderate performance $(40 \%-49 \%)$; ' 2 ' basic performance $(30 \%-39 \%)$; and ' 1 ' was allocated when the learning outcome had not been achieved $(0 \%-29 \%)$. A midyear grade point average was calculated by adding all the learning areas together. The June mid-year assessments were compiled and scored by the applicable teachers. The ANA tests were compiled nationally by the Department of Basic Education and only scored by the teachers, making it a more objective, representative and comparative assessment of learners' academic achievements in South Africa.

\section{Statistic procedure}

The Statistica for Windows 2014 computer program (Statsoft) was used to analyse the data (StatSoft 2014). For descriptive purposes, data were analysed according to means (M), standard deviations (SD) and minimum and maximum values (StatSoft 2014). Independent $t$-testing was used to determine differences between boys and girls. Practical significance of differences was calculated by means of effect sizes (ES), by dividing the mean difference between boys and girls through the biggest standard deviation. For the interpretation of practical significance the following guidelines were used: $d \geq 0.3$ indicated a small effect; $d \geq 0.5$ indicated a moderate effect and $d \geq 0.8$ indicated a large effect (Cohen 1988). Because of the small group of learners identified with DCD the Mann-Whitney non-parametric test was also used to confirm practically significant differences, where $d \geq 0.1$ indicated a small effect; $d \geq 0.3$ indicated a moderate effect and $d \geq 0.5$ indicated a large effect.

\section{Ethical consideration}

Ethical clearance (based on the Helsinki guidelines) for the implementation of the NW-CHILD study has been received from the Ethics Committee of the North-West University (No. NW-00070-09-A1). Permission was also obtained from the Department of Basic Education of the North West Province, South Africa.

Principals of the respective identified schools also gave permission for the data collection during school hours. The parents or legal guardians of all Grades 3 and 4 learners who participated in the study at each of the selected schools received informed consent forms, which they had to complete. All the learners also received assent forms and only learners who themselves and whose parents or legal guardians gave informed permission underwent the testing.

\section{Results}

Table 1 displays the number of learners in the group and by gender in the different DCD categories, where descriptive group characteristics are provided according to percentile cut-off values of the MABC- 2 . In total, $18.7 \%$ of boys $(n=23)$ and $24.49 \%$ of girls $(n=24)$ fell in the group below the 16 th percentile, which classified them with possible DCD. When applying the diagnostic criteria of the DSM-5, 5.69\% of boys $(n=7)$ and $7.14 \%$ of girls $(n=7)$ were classified with severe DCD (6.33\%). The remaining 207 (93.67\%) learners fell in the non-DCD group and were regarded as typically developing learners.

TABLE 1: Percentage of learners in different developmental coordination disorder categories in the group and by gender.

\begin{tabular}{|c|c|c|c|c|c|c|c|}
\hline \multirow[t]{2}{*}{ DCD categories } & \multirow[t]{2}{*}{ Variables } & \multirow[t]{2}{*}{$n$} & \multirow[t]{2}{*}{$\%$} & \multicolumn{4}{|c|}{ Gender } \\
\hline & & & & Boys & $\%$ & Girls & $\%$ \\
\hline \multirow{2}{*}{$\begin{array}{l}\text { DCD according to } \\
\text { MABC-2 percentiles }\end{array}$} & $<16 \%$ & 47 & 21.27 & 23 & 18.70 & 24 & 24.49 \\
\hline & $>16 \%$ & 174 & 78.73 & 100 & 81.30 & 74 & 75.51 \\
\hline Total & - & 221 & 100.00 & 123 & 100.00 & 98 & 100.00 \\
\hline \multirow{2}{*}{$\begin{array}{l}\text { DCD according to DSM-5 } \\
\text { criteria }\end{array}$} & $\mathrm{DCD}$ & 14 & 6.33 & 7 & 5.69 & 7 & 7.14 \\
\hline & Non-DCD & 207 & 93.67 & 116 & 94.31 & 91 & 92.86 \\
\hline Total & - & 221 & 100.00 & 123 & 100.00 & 98 & 100.00 \\
\hline
\end{tabular}

$n$, number of learners; $\%$, percentage

$D C D$, developmental coordination disorder; MABC-2, movement assessment battery for children, second edition; DSM-5, Diagnostic and Statistical Manual of Mental Disorders, fifth edition. 
Table 2 reflects the distribution of boys and girls with DCD according to ethnicity and socio-economic status when classified with DCD using the DSM- 5 diagnostic criteria $(n=$ 14) and those classified achieving lower than the 16th percentile $(n=47)$.

The majority of learners with DCD were identified from Quintile 1 (three boys, two girls) and Quintile 2 (four boys, three girls) schools, which represented schools with low socio-economic status, while one learner each from a Quintile 4 and a Quintile 5 school were present in the group. An equal number of boys and girls were identified with DCD (seven learners each). All of these boys and girls were black or mixed race, while no white learners were classified with DCD.

The number of learners who were classified as below the 16th percentile according to the MABC-2 was fairly equally distributed amongst Quintile 1 to Quintile 4 schools, with only three learners identified from Quintile 5 schools. Representation of different racial groups in the possible DCD group indicated a greater prevalence amongst black learners, with 22 of 24 girls and 19 of 23 boys of African descent. It is however important to highlight that more black learners were part of the study sample.

In Table 3 the boys $(n=123)$ and girls $(n=98)$ without DCD, representing typical children, and those in the DSM-5 DCD group ( $n=14 ; 7$ boys, 7 girls) were compared with regard to their MABC-2 scores. Although no statistically significant ( $p$ $<0.05)$ gender differences were established in the groups with or without DCD, medium to large practically significant differences were found between the MABC-2 scores of boys and girls in the DCD group. Boys performed significantly more poorly than the girls in manual dexterity, balance and the total standard score. A borderline small practically significant difference was seen in the aiming and catching task, where the boys with DCD performed better than the

TABLE 2: Demographics of learners with developmental coordination disorder according to the Diagnostic and Statistical Manual of Mental Disorders, fifth edition diagnostic criteria.

\begin{tabular}{|c|c|c|c|c|c|}
\hline \multicolumn{3}{|c|}{$\begin{array}{l}\text { Possible DCD } \\
\text { (<16th percentile) }\end{array}$} & \multicolumn{3}{|c|}{$\begin{array}{l}\text { DCD (according to DSM-5 } \\
\text { diagnostic criteria) }\end{array}$} \\
\hline Gender & $n=47$ & Ethnicity $(n)$ & Gender & $n=14$ & Ethnicity (n) \\
\hline \multirow[t]{2}{*}{ Girls } & 24 & White - 2 & Girls & 7 & Other - 1 \\
\hline & & Black - 22 & & & Black - 6 \\
\hline \multirow[t]{2}{*}{ Boys } & 23 & White - 4 & Boys & 7 & White -0 \\
\hline & & Black - 19 & & & Black - 7 \\
\hline SES & $n=47$ & $\begin{array}{l}\text { Gender } \\
\text { distribution (n) }\end{array}$ & SES & $n=14$ & $\begin{array}{l}\text { Gender } \\
\text { distribution ( } n \text { ) }\end{array}$ \\
\hline \multirow[t]{2}{*}{ Quintile 1-L } & 8 & Girls - 3 & Quintile 1-L & 5 & Girls - 2 \\
\hline & & Boys -5 & & & Boys -3 \\
\hline \multirow[t]{2}{*}{ Quintile 2} & 10 & Girls - 5 & Quintile 2 & 7 & Girls - 3 \\
\hline & & Boys -5 & & & Boys -4 \\
\hline \multirow[t]{2}{*}{ Quintile 3} & 12 & Girls - 7 & Quintile 3 & 0 & Girls - 0 \\
\hline & & Boys -5 & & & Boys -0 \\
\hline \multirow[t]{2}{*}{ Quintile 4} & 14 & Girls - 6 & Quintile 4 & 1 & Girls - 1 \\
\hline & & Boys -8 & & & Boys -0 \\
\hline \multirow[t]{2}{*}{ Quintile 5-H } & 3 & Girls - 3 & Quintile 5-H & 1 & Girls - 1 \\
\hline & & Boys - 0 & & & Boys - 0 \\
\hline
\end{tabular}

$n$, number of learners; SES, socio-economic status; L, low; H, high; DCD, developmental coordination disorder; DSM-5, Diagnostic and Statistical Manual of Mental Disorders, fifth edition. girls with $\mathrm{DCD}(d=0.28)$. No practically significant differences were found amongst learners without DCD in any of the MABC-2 subsections or the total score.

Table 4 compares the academic achievement of typically developing boys and girls. According to these results typically developing girls performed statistically and practically significantly better than boys in Afrikaans, Setswana, English and Maths $(p<0.05)$ during the June assessment. Boys outperformed girls in Natural Sciences during the June assessment and in Setswana during the national assessment. The mean percentages that are displayed in the table as well as the practical significance of differences that were established indicate bigger gender differences in language-related learning areas compared to in Mathematics.

Table 5 (DCD group <16th percentile) and Table 6 (DCD group DSM- 5 criteria) summarise the differences in academic achievement between boys and girls during the mid-year (June) school assessment and the ANA exams in 2013. Table 5 shows that the grade point averages of the girls that were attained in the June assessment and the averages in most of the learning areas were higher compared to the boys, while the boys only displayed higher averages in Afrikaans (59.85\% vs. $57.11 \%, p>0.05)$ and Natural Sciences $(64.50 \%$ vs. $58 \%$, $p>0.05)$. Although no statistically significant differences were found, practical significant differences of a medium effect were found in the averages that were obtained in Afrikaans $(d=0.38 ; d=0.23$, for the $T$-test and Mann-Whitney U-test, respectively). Girls obtained higher Setswana $(40.0 \%$ vs. $31.13 \%, p=0.05)$ and Mathematics percentages $(42.78 \%$ vs. $40.39 \%, p>0.05)$. In Setswana these gender differences were also practically significant $(d=0.33 ; d=0.19$, for the T-test and Mann-Whitney U-test, respectively).

Table 6 shows that girls who were identified with DCD according to the DSM-5 diagnostic criteria achieved a statistically and practically significant higher grade point average $(43.56 \%, p=0.04, d=1.16)$ in their June marks than boys with DCD. This gender difference is also confirmed by

TABLE 3: Differences between boys and girls with and without developmental coordination disorder in the different MABC-2 subdivisions.

\begin{tabular}{|c|c|c|c|c|c|c|c|c|}
\hline \multirow[t]{2}{*}{ Variables } & \multicolumn{2}{|c|}{ Boys $(n=123)$} & \multicolumn{2}{|c|}{ Girls $(n=98)$} & \multicolumn{4}{|c|}{ Significance of differences } \\
\hline & M & SD & M & SD & $d f$ & $t$ & $p$ & $d$ \\
\hline \multicolumn{9}{|c|}{ Manual dexterity standard score } \\
\hline $\mathrm{DCD}^{\prime \prime}(n=14)$ & 3.86 & 1.57 & 4.71 & 1.11 & 12 & -1.18 & 0.26 & $0.54^{\# \#}$ \\
\hline Without DCD $(n=207)$ & 8.34 & 2.62 & 7.87 & 2.28 & 205 & 1.38 & 0.17 & 0.18 \\
\hline \multicolumn{9}{|c|}{ Aiming and catching standard score } \\
\hline $\mathrm{DCD}^{\prime \prime}(n=14)$ & 9.71 & 2.06 & 9.14 & 1.77 & 12 & 0.56 & 0.59 & $0.28^{\#}$ \\
\hline Without DCD $(n=207)$ & 11.24 & 8.77 & 11.58 & 2.34 & 205 & -0.40 & 0.69 & 0.04 \\
\hline \multicolumn{9}{|c|}{ Balance standard score } \\
\hline $\mathrm{DCD}^{\prime \prime}(n=14)$ & 6.71 & 2.56 & 8.86 & 2.85 & 12 & -1.48 & 0.17 & $0.75^{\# \#}$ \\
\hline Without DCD $(n=207)$ & 10.75 & 3.05 & 11.39 & 2.92 & 205 & -1.54 & 0.13 & 0.12 \\
\hline \multicolumn{9}{|c|}{ MABC-2 total standard score } \\
\hline $\mathrm{DCD}^{\prime \prime}(n=14)$ & 5.29 & 1.70 & 6.43 & 0.98 & 12 & -1.54 & 0.15 & $0.67^{\# \#}$ \\
\hline Without DCD $(n=207)$ & 9.45 & 2.33 & 10.00 & 2.40 & 205 & -1.66 & 0.10 & 0.23 \\
\hline
\end{tabular}

$\mathrm{M}$, mean values; SD, standard deviation; MABC-2, Movement Assessment Battery for Children, second edition; DCD, developmental coordination disorder, according to the DSM-5 diagnostic criteria.

$p \leq 0.05$.

${ }^{\#} d \geq 0.3 ;{ }^{\#} d \geq 0.5 ; d \geq 0.8$. 
TABLE 4: Gender differences in academic achievement of typical developing learners (>16th percentile).

\begin{tabular}{|c|c|c|c|c|c|c|c|c|c|c|c|}
\hline \multirow{2}{*}{$\begin{array}{l}\text { Assessment } \\
\text { opportunities }\end{array}$} & \multirow[t]{2}{*}{ Learning area } & \multicolumn{3}{|c|}{ Boys } & \multicolumn{3}{|c|}{ Girls } & \multicolumn{4}{|c|}{ Significance of differences $-t$-test } \\
\hline & & $n$ & $\mathrm{M} \%$ & SD & $n$ & $\mathrm{M} \%$ & SD & $t$ & $d f$ & $p$ & Effect size \\
\hline \multirow[t]{7}{*}{ June 2013} & Afrikaans & 34 & 62.65 & 11.03 & 26 & 69.42 & 10.52 & -2.41 & 58 & $0.02 *$ & $0.61^{\# \#}$ \\
\hline & Setswana & 60 & 45.37 & 22.10 & 47 & 54.28 & 15.76 & -2.33 & 105 & $0.02 *$ & $0.40^{\#}$ \\
\hline & English & 94 & 49.15 & 21.46 & 73 & 57.66 & 20.97 & -2.57 & 165 & $0.01 *$ & $0.40^{\#}$ \\
\hline & Mathematics & 94 & 59.26 & 16.24 & 73 & 65.48 & 12.26 & -2.76 & 165 & $0.00 *$ & $0.38^{\#}$ \\
\hline & LO & 94 & 51.48 & 22.38 & 73 & 55.44 & 25.41 & -1.07 & 165 & 0.29 & 0.16 \\
\hline & NS & 70 & 56.56 & 20.54 & 64 & 56.03 & 21.45 & 0.14 & 132 & 0.88 & 0.02 \\
\hline & GPA & 94 & 52.73 & 17.53 & 73 & 58.98 & 16.26 & -2.36 & 165 & $0.02 *$ & $0.36^{\#}$ \\
\hline \multirow[t]{4}{*}{ ANA 2013} & Afrikaans & 23 & 67.39 & 17.52 & 20 & 71.60 & 11.28 & 0.92 & 41 & 0.36 & 0.24 \\
\hline & Setswana & 24 & 22.12 & 16.01 & 16 & 20.00 & 16.00 & 0.41 & 38 & 0.68 & 0.13 \\
\hline & English & 43 & 49.26 & 23.80 & 36 & 56.44 & 18.28 & -1.48 & 77 & 0.14 & $0.30^{\#}$ \\
\hline & Mathematics & 89 & 42.36 & 21.74 & 72 & 42.75 & 20.60 & -0.12 & 159 & 0.91 & 0.02 \\
\hline
\end{tabular}

n, number of learners; M\%, average academic achievement; SD, standard deviation; NS, Natural Sciences; LO, Life Orientation; SS, Social Sciences; GPA, mid-year grade point average; ANA, Annual National Assessment.

Note: Bold values indicate the 'larger' average between boys and girls.

$* p \leq 0.05$

${ }^{\#} d \geq 0.3 ;{ }^{\#} d \geq 0.5$

TABLE 5: Gender differences in academic achievement of learners with possible developmental coordination disorder (<16th percentile).

\begin{tabular}{|c|c|c|c|c|c|c|c|c|c|c|c|c|c|}
\hline \multirow{3}{*}{$\begin{array}{l}\text { Assessment } \\
\text { opportunities }\end{array}$} & \multicolumn{13}{|c|}{ Possible DCD (< 16th percentile) } \\
\hline & \multirow[t]{2}{*}{ Learning area } & \multicolumn{3}{|c|}{ Boys } & \multicolumn{3}{|c|}{ Girls } & \multicolumn{4}{|c|}{ Significance of differences $-t$-test } & \multicolumn{2}{|c|}{ Mann-Whitney U-test } \\
\hline & & $N$ & $M \%$ & SD & $n$ & $M \%$ & SD & $t$ & $d f$ & $p$ & Effect size & $p$ & Effect size \\
\hline \multirow[t]{8}{*}{ June 2013} & Afrikaans & 8 & 64.50 & 14.01 & 9 & 58.00 & 17.20 & 0.85 & 15 & 0.41 & $0.38^{\#}$ & 0.336 & $0.23^{\$ \$}$ \\
\hline & Setswana & 15 & 51.73 & 23.33 & 15 & 53.07 & 11.10 & -0.20 & 28 & 0.84 & 0.06 & 0.950 & 0.01 \\
\hline & English & 23 & 52.52 & 27.47 & 24 & 57.33 & 19.72 & -0.69 & 45 & 0.49 & 0.18 & 0.640 & 0.07 \\
\hline & Mathematics & 23 & 61.22 & 15.45 & 24 & 63.04 & 16.44 & -0.39 & 45 & 0.70 & 0.11 & 0.558 & 0.09 \\
\hline & LO & 23 & 54.26 & 24.03 & 24 & 56.17 & 20.38 & -0.29 & 45 & 0.77 & 0.08 & 0.798 & 0.04 \\
\hline & SS & 13 & 56.46 & 19.73 & 18 & 60.61 & 20.37 & -0.57 & 29 & 0.58 & 0.20 & 0.459 & 0.13 \\
\hline & NS & 13 & 59.85 & 15.83 & 18 & 57.11 & 17.65 & 0.44 & 29 & 0.66 & 0.15 & 0.508 & 0.12 \\
\hline & GPA & 23 & 53.88 & 18.36 & 24 & 57.46 & 13.25 & -0.77 & 45 & 0.45 & 0.20 & 0.509 & 0.10 \\
\hline \multirow[t]{4}{*}{ ANA 2013} & Afrikaans & 0 & - & - & 3 & 78.67 & 13.32 & - & 1 & - & - & - & - \\
\hline & Setswana & 8 & 31.13 & 24.46 & 6 & 40.00 & 27.07 & -0.64 & 12 & 0.53 & $0.33^{\#}$ & 0.477 & $0.19^{\$ \$}$ \\
\hline & English & 15 & 57.33 & 22.34 & 15 & 54.67 & 11.00 & 0.41 & 28 & 0.68 & 0.12 & 0.724 & 0.06 \\
\hline & Mathematics & 23 & 40.39 & 17.41 & 23 & 42.78 & 19.55 & -0.44 & 44 & 0.66 & 0.12 & 0.852 & 0.03 \\
\hline
\end{tabular}

$n$, number of learners; M\%, average academic achievement; SD, standard deviation; NS, Natural Sciences; LO, Life Orientation; SS, Social Sciences; GPA, mid-year grade point average; ANA, Annua National Assessment.

$* p \leq 0.05$

${ }^{\#} d \geq 0.3$.

Mann-Whitney: $10 \%$ level of significance*; ${ }^{\mathrm{s}} d \geq 0.1 ;{ }^{\mathrm{s}} d \geq 0.3 ;{ }^{\mathrm{ss}} d \geq 0.5$.

TABLE 6: Gender differences in academic achievement of learners with developmental coordination disorder according to the Diagnostic and Statistical Manual of Mental Disorders, fifth edition diagnostic criteria.

\begin{tabular}{|c|c|c|c|c|c|c|c|c|c|c|c|c|c|}
\hline \multirow{3}{*}{$\begin{array}{l}\text { Assessment } \\
\text { opportunities }\end{array}$} & \multicolumn{13}{|c|}{ DCD according to DSM-5 diagnostic criteria } \\
\hline & \multirow[t]{2}{*}{ Learning area } & \multicolumn{3}{|c|}{ Boys } & \multicolumn{3}{|c|}{ Girls } & \multicolumn{4}{|c|}{ Significance of differences $-t$-test } & \multicolumn{2}{|c|}{ Mann-Whitney U-test } \\
\hline & & $n$ & $M \%$ & SD & $n$ & $M \%$ & SD & $t$ & $d f$ & $p$ & Effect size & $p$ & Effect size \\
\hline \multirow[t]{8}{*}{ June 2013} & Afrikaans & 0 & - & - & 2 & 40.00 & 5.66 & - & 0 & - & - & - & - \\
\hline & Setswana & 7 & 33.43 & 18.25 & 5 & 46.80 & 15.48 & -1.33 & 10 & 0.21 & $0.73^{\# \#}$ & 0.194 & $0.38^{\$ \$}$ \\
\hline & English & 7 & 18.14 & 9.27 & 7 & 40.14 & 20.72 & -2.56 & 12 & $0.02 *$ & $1.06^{\# \# \#}$ & $0.055^{*}$ & $0.51^{\$ \$ \$}$ \\
\hline & Mathematics & 7 & 47.57 & 11.31 & 7 & 53.71 & 18.91 & -0.74 & 12 & 0.48 & $0.32^{\#}$ & 0.522 & 0.17 \\
\hline & LO & 7 & 28.57 & 6.13 & 7 & 38.57 & 13.95 & -1.74 & 12 & 0.11 & $0.72^{\# \#}$ & 0.304 & $0.27^{\$ \$}$ \\
\hline & SS & 2 & 37.00 & 7.07 & 5 & 51.40 & 32.14 & -0.60 & 5 & 0.58 & $0.45^{\#}$ & 0.846 & 0.07 \\
\hline & NS & 2 & 38.00 & 5.66 & 5 & 40.80 & 11.21 & -0.32 & 5 & 0.76 & 0.25 & 0.846 & 0.07 \\
\hline & GPA & 7 & 31.68 & 8.66 & 7 & 43.56 & 10.28 & -2.34 & 12 & $0.04 *$ & $1.16^{\# \# \# ~}$ & $0.055^{*}$ & $0.51^{\$ \$ \$}$ \\
\hline \multirow[t]{4}{*}{ ANA 2013} & Afrikaans & 0 & - & - & 1 & 64.00 & 0.00 & - & 0 & - & - & - & - \\
\hline & Setswana & 4 & 11.50 & 7.55 & 3 & 20.27 & 8.33 & -1.53 & 5 & 0.19 & $1.10^{\# \# \# ~}$ & 0.285 & $0.40^{\$ \$}$ \\
\hline & English & 3 & 26.67 & 10.26 & 3 & 50.00 & 12.17 & -2.54 & 4 & $0.06^{*}$ & $1.92^{\# \# \#}$ & $0.081^{*}$ & $0.71^{\$ \$ \$}$ \\
\hline & Mathematics & 7 & 23.14 & 11.82 & 7 & 28.29 & 12.08 & -0.80 & 12 & 0.44 & $0.43^{\#}$ & 0.442 & $0.21^{\$ \$}$ \\
\hline
\end{tabular}

DSM-5, Diagnostic and Statistical Manual of Mental Disorders, fifth edition; DCD, developmental coordination disorder; $n$, number of learners; M\%, average academic achievement; SD, standard deviation; NS, Natural Sciences; LO, Life Orientation; SS, Social Sciences; GPA, mid-year grade point average; ANA, Annual National Assessment.

Note: Bold values indicate "larger" average between boys and girls.

${ }^{*} p \leq 0.05$.

${ }^{\#} d \geq 0.3 ; \# d \geq 0.5 ;$

Mann-Whitney: $10 \%$ level of significance*; ${ }^{\$} d \geq 0.1 ; \$ \$ d \geq 0.3 ; \$ \$ \$ d \geq 0.5$. 
non-parametric $(d)$ statistics $(p=0.055 ; d=0.51)$. The girls with DCD also obtained higher percentages $(p>0.05)$ than the boys with DCD in six of the seven learning areas: English (40.14\%), Setswana (46.80\%), Mathematics (53.71\%), Life Orientation (38.57\%), Social Sciences $(51.40 \%)$ and Natural Sciences $(40.80 \%)$. Of these, practically significant gender differences with a medium effect were found in Setswana $(d=0.73 ; d=0.38)$ and Life Orientation $(d=0.72 ; d=0.27)$. It transpires that girls with DCD achieved better marks in Setswana, Life Orientation and English in particular. These academic differences were also confirmed by the results obtained during the ANA exams where girls also achieved higher marks in Setswana (20.27\%, $p>0.05)$, English (50.0\%, $p>0.05)$ and Mathematics (28.29\%, $p>0.05)$. Practically significant differences showing a large effect were found in Setswana performance $(d=1.10 ; d=0.40)$, while a moderate practically significant effect was indicated in Mathematics performance $(d=0.43 ; d=0.21)$. Statistically $(p=0.06)$ and practically significant $(d=1.92 ; d=0.71)$ differences were also established between boys and girls in the percentages that they obtained in English.

When comparing the marks obtained by typically developing children with DCD children in all learning areas and the grade point average (Tables 4 through 6), a clear lowering of the marks was apparent when motor difficulties were taken in consideration. Gender differences were also bigger in DCD children, as was especially evident when comparing the differences between maths and the mid-year grade points of typically developing children (Table 4) and boys and girls classified with DCD (Table 6). Typically developing boys and girls showed mid-year grade point averages of $52.73 \%$ and $58.98 \%$, respectively, compared to $31.68 \%$ for boys and $43.56 \%$ for girls with DCD.

\section{Discussion}

This study aimed to determine if differences exist in the academic achievement of boys and girls who are identified with DCD. A DCD prevalence of $6.33 \%$, representing seven boys and seven girls, was found in the group, based on the diagnostic criteria of the DSM-5, which corresponds with values of $5 \%$ to $6 \%$ that are reported for children between the ages of 5 and 11 years in the DSM-5 (APA 2013). Furthermore, $47(21.27 \%)$ of the total group were also classified in the possible DCD group. In Bloemfontein, South Africa, a high prevalence was also reported in an urban environment, where $15 \%$ of the learners displayed possible DCD (De Milander et al. 2014). This prevalence (15\%) is based on the results of a population-based study, where the DSM-5 diagnostic criteria were not applied, as was the case when classifying our group of 47 learners (21.27\%). Amongst older children in other countries from backgrounds different to South Africa, higher and more similar DCD occurrences to our results are reported, where 19\% of 10-12-year-old Greek children and $8 \%$ of $10-13$-year-old Canadian children also displayed DCD characteristics without using the specific DSM-5 criteria to determine DCD (Tsiotra et al. 2006).
An equal number of boys and girls were categorised in the DCD group, when the DSM-5 diagnostic criteria were applied. This boy-girl ratio differs from most studies on 5-10-year-old children, where researchers have reported a higher DCD prevalence in boys (Asonitou et al. 2012; Cheng et al. 2014; De Milander et al. 2014; Lingam et al. 2009). Although the studies of Cairney et al. (2005:78) and Dewey et al. (2002:909) were completed on slightly older DCD children (12-14 years old) than ours, they however also reported no differences in the boy-girl ratios. Our results furthermore indicated that learners from low socio-economic circumstances displayed a greater tendency towards DCD as the highest number of learners in the group was identified from lower socio-economic-status schools. Cloete et al. (2006:23) also argue that poor socio-economic conditions give rise to a greater prevalence of DCD amongst South African children, where a large group of learners in their study from a low socio-economic area was classified with moderate and severe DCD. An association between socio-economic status and probable DCD is also reported by Santos et al. (2015:82), where a greater proportion of learners with possible DCD came from low socio-economic environments.

The results of the study confirmed differences in the academic achievement of boys and girls with DCD. Boys with DCD displayed weaker academic achievement than girls did, whereas girls with DCD performed practically $(d=1.06)$ and statistically significantly $(p=0.02)$ better than boys, particularly in language-related learning areas. Lingam et al. (2010:1115) state that both genders displayed an increased risk for reading problems if DCD was present and that girls with DCD are more prone to backlogs in reading skills than boys are, taking into account that reading skills form part of language-related learning areas. Findings between these two studies might differ because of different population samples as participants were 7 years of age and from the United Kingdom, compared to 10-year-olds from South Africa. Researchers also report that boys with DCD struggle more in the classroom set-up with language-related tasks, including mathematical tasks that have strong underlying language components (Alt et al. 2014; Korhonen \& Linnanmäki 2012; Van Lill 2011). Reading is used during various academic skills and in this regard, Van Lill (2011:27) is of the opinion that meticulous mathematical calculations are strongly embedded in language and are related to language skills in mathematical instructions. Language being an important factor in mathematical task comprehension can also be a reason why girls in our study outperformed boys in both reading and maths, even though literature states that boys are in general stronger achievers in mathematical tasks.

Very little research focuses on gender differences between boys and girls with DCD, while various researchers state that typically developing boys display better mathematical skills (Driessen \& Van Langen 2013; Else-Quest et al. 2010; Krinzinger et al. 2012; Mills et al. 1993; Robinson et al. 1996), compared to typically developing girls, who display better language skills (Driessen \& Van Langen 2013). These findings are in contradiction with our findings, where typically 
developing girls outperformed boys in most of the learning areas. Although one can distinguish between language and mathematical skills, various researchers are of the opinion that certain aspects of Mathematics strongly relate to language and reading skills (Alt et al. 2014; Korhonen \& Linnanmäki 2012; Van Lill 2011). As stated previously, reading is therefore indirectly involved in the findings on academic achievement in various learning areas. Voyer and Voyer (2014:1190) report that the greatest gender differences in academic achievements lie in language learning areas, while mathematical performance reflects the least differences between typically developing boys and girls. This is in accordance with our findings where typically developing girls outperformed boys in most learning areas, with the biggest differences present in language-related learning areas. Amongst DCD learners our findings also record the largest gender differences to be present in language-related learning areas, while smaller differences were found in Mathematics and Life Orientation, favouring girls with DCD. Executive function also seems to play a role in academic achievement and some researchers identify a definite difference between boys' and girls' executive function abilities, while others report that differences aren't significant. Blair, Raver and Berry (2013:560) are of the opinion that boys' executive function ability develops better than that of girls, while non-significant differences in executive function development between genders are also reported (DeWan 2006). For girls, increased executive function seems to be present during activities involving language (DeWan 2006; Hanlon, Thatcher \& Cline 1999), attention, visual-motor speed and visual short-term memory (Lax et al. 2015). According to Hanlon et al. (1999:505), boys on the other hand portray better visual-spatial and planning abilities than girls. Carlson, Rowe and Curby (2013:530) also argue that visualspatial integration seems to be an important predictor for achievement in maths and writing skills and that this ability is consequently significant for achievement in maths throughout childhood and adolescence years. Contrary to the findings of Hanlon et al. (1999:505), a study conducted by DeWan (2006:42) reported no significant gender differences in visualspatial and planning abilities. According to Aadland et al. (2017:16) executive function is not only significantly related to academic achievement but also motor skills amongst 10-yearolds in Norway.

As displayed in the MABC-2 results the boys in the group performed practically significantly more poorly in manual dexterity and balance, with performance in the aiming and catching tasks more or less the same compared to the girls. These results confirmed that boys portrayed poorer coordination abilities than girls, with specific regard to two of the three coordination components in the MABC-2 (Table 3), which might be suggestive of perceptual differences between genders. Different perceptual skills include body awareness, spatial orientation, directionality, temporal awareness, balance, bilateral integration and depth perception (Gallahue, Ozmun \& Goodway 2012). Backlogs in these perceptual skills or the presence of poor coordination could arguably be a possible role player in the weaker academic achievement as attained by the boys with DCD, as perceptual skills relate strongly to abilities used especially for mathematical achievement (Frick \& Möhring 2016). Because of the involvement of underlying neural structures (Diamond 2000) in both motor coordination and cognitive tasks, a lack of motor coordination will impact academic achievement negatively. The poorer underlying balance and hand skills present in boys with DCD in this study have also contributed to coordination problems of a more serious nature. Vuijk et al. (2011:280) state in this regard that relationships occur between balance and mathematics, dexterity and spelling, and between ball skills and reading ability, while gross motor skills (Lopes et al. 2013), fine motor skills (Luo et al. 2007; Piek, Baynam \& Barrett 2006) and spatial orientation (Richardson, Hunt \& Richardson 2014) are also reported to play an important role in scholastic ability and academic achievement.

In summary our results also confirmed poorer academic achievement in both boys and girls with DCD compared to typically developing children, where the decrease was also higher in boys as seen in the grade point average. These results substantiate the co-occurrence of motor and cognitive performance problems (Diamond 2000; Westendorp et al. 2011).

\section{Conclusions}

This study confirmed academic underachievement in children with DCD, as the highest mid-year grade point average attained for any learning area was 53.0\%. A significant difference in overall academic achievement (especially in mid-year grade point average and English achievement) amongst boys and girls with DCD has also been established in this study. Girls with DCD (DSM-5 criteria) performed significantly better with regard to their mid-year grade point average $(44.0 \%)$ than boys with DCD (32.0\%). They also achieved significantly better language and Mathematics marks than boys with DCD in the ANA, which is regarded as a more objective assessment of learners' academic achievement, because it is based on national compared benchmarks of the Basic Education system of South Africa. The considerably poorer motor skills of boys with DCD compared to those of the girls in the group have probably played a contributing role in these differences as problems of these nature are linked to scholastic ability.

Although the research was done with a randomly selected group of learners, only one province of South Africa was involved in the study. The final group size of 14 learners with DCD identified from the larger group of 221 was small, which consequently leads to shortcomings regarding the generalisability of the results. It is therefore recommended that a larger sample group as well as learners from other age groups should be used in other parts of South Africa for future studies to further investigate and confirm the above results. Differences in academic achievement amongst learners of different genders with DCD was also only superficially investigated in this study, as symptoms of academic achievement as displayed in the marks obtained in tests, and not psychometric assessments of cognitive ability, were used 
to compare boys and girls. However, the practically significant differences that were established between the genders in this study necessitate a more probing investigation into more deep-seated differences in executive function between the genders. It is further recommended that teachers should be made aware of gender differences that could influence the DCD child's academic achievement in order to support them with adjusted learning strategies in the classroom. Within the classroom set-up these children will show poor motor planning abilities and they might also struggle with the writing of sentences, spelling, execution of mathematical equations and successfully doing tasks against time.

\section{Acknowledgements}

We acknowledge the Medical Research Council (MRC) of South Africa, the National Research Foundation (NRF) and the South African Sugar Association (SASA) for the grants that they offered for the completion of this project. Our sincere thanks are also expressed towards the 2013 Kinderkinetics Honours students at the NWU, for their assistance in collecting the data.

\section{Competing interests}

The authors declare that they have no financial or personal relationships which may have inappropriately influenced them in writing this article.

\section{Authors' contributions}

A.E.P. was the project leader and conceptualised the study. D.C. and E.D.W. were responsible for assisting with project administration. A.E.P., D.C. and E.D.W. were responsible for collecting data, interpreting data and attributing to the writing of the manuscript.

\section{References}

Aadland, K.N., Moe, V.F., Aadland, E., Anderssen, S.A., Resaland, G.K. \& Ommundsen, Y., 2017, 'Relationships between physical activity, sedentary time, aerobic fitness, motor skills and executive function and academic performance in children Mental Health and Physical Activity 12, 10-18. https://doi.org/10.1016/j. mhpa.2017.01.001

Alloway, T.P., 2007, 'Working memory, reading and mathematical skills in children with developmental coordination disorder', Journal of Experimental Child Psychology 96, 20-36. https://doi.org/10.1016/j.jecp.2006.07.002

Alt, M., Arizmendi, G.D. \& Beal, C.R., 2014, 'The relationship between mathematics and language: Academic implications for children with specific language impairment and English language learners', Language, Speech, and Hearing Services in Schools 45, 220-233. https://doi.org/10.1044/2014_LSHSS-13-0003

American Psychiatric Association, 2013, Diagnostic and statistical manual of mental disorders, 5th edn., American Psychiatric Association, Washington, DC.

Archibald, L.M.D. \& Alloway, T.P., 2008, 'Comparing language profiles: Children with specific language impairment and developmental coordination disorder', International Journal of Language and Communication Disorders 43(2), 165-180. https://doi.org/10.1080/13682820701422809

Asonitou, K., Koutsouki, D. \& Charitou, S., 2010, 'Motor skills and cognitive abilities as a precursor of academic performance in children with and without DCD', Procedia Social and Behavioral Sciences 5, 1702-1707. https://doi.org/10.1016/j. sbspro.2010.07.350

Asonitou, K., Koutsouki, D., Kourtessis, T. \& Charitou, S., 2012, 'Motor and cognitive performance differences between children with and without developmental coordination disorder (DCD)', Research in Developmental Disabilities 33, 9961005. https://doi.org/10.1016/j.ridd.2012.01.008

Asonitou, K., Tsiganos, G., Kourtessis, T., Strofylla, G. \& Koutsouki, D., 2014, ‘Assessment of cognitive abilities in preschool children with and without developmental coordination disorder', International Journal for Cross-disciplinary Subjects in Education 5, 1571-1576. https://doi.org/10.20533/ijcdse.2042.6364.2014.0220
Auxter, D., Pyfer, J. \& Huettig, C., 2010, Principles and methods of adapted physical education and recreation, 11th edn., McGraw Hill, New York.

Blair, C., Raver, C.C. \& Berry, D.J., 2013, 'Two approaches to estimating the effect of parenting on the development of executive function in early childhood', Developmental Psychology 50(2), 554-565. https://doi.org/10.1037/a0033647

Cairney, J., Hay, J., Faught, B., Mandigo, J. \& Flouris, A., 2005, 'Developmental coordination disorder, self-efficacy toward physical activity, and play: Does gende matter?', Adapted Physical Activity Quarterly 22, 67-82. https://doi.org/10.1123/ apaq.22.1.67

Carlson, A.G., Rowe, E. \& Curby, T.W., 2013, 'Disentangling fine motor skills' relations to academic achievement: The relative contributions of visual-spatial integration and visual-motor coordination', The Journal of Genetic Psychology 174(5), 514533. https://doi.org/10.1080/00221325.2012.717122

Cheng, C.H., Chen, J.Y., Tsai, C.L., Shen, M.L. \& Cherng, R.J., 2011, 'Reading and writing performances of children 7-8 years of age with developmental coordination disorder in Taiwan', Research in Developmental Disabilities 32, 2589-2594. https://doi.org/10.1016/j.ridd.2011.06.017

Cheng, C.H., Ju, Y.Y., Chang, H.W., Chen, C.L., Pei, Y.C., Tseng, K.C. \& Cheng, H.Y.K., 2014 'Motor impairments screened by the Movement Assessment Battery for children-2 are related to the visual-perceptual deficits in children with developmental coordination disorder', Research in Developmental Disabilities 35 2172-2179. https://doi.org/10.1016/j.ridd.2014.05.009

Cloete, E., Pienaar, A.E. \& Coetzee, M., 2006, 'Lae fisieke aktiwiteit se verband met ontwikkelingskoördinasieversteuring: Thusa bana-studie', South African Journal of Research in Sport, Physical Education and Recreation 28(1), 13-27. https://doi. org/10.4314/sajrs.v28i1.25928

Coe, D.P., Peterson, T., Blair, C., Shutten, M.C. \& Peddie, H., 2013, 'Physical fitness, academic achievement, and socioeconomic status in school-aged youth', Journal of School Health 89(7), 500-507. https://doi.org/10.1111/josh.12058

Cohen, J., 1988, Statistical power analysis for the behavioural sciences, 2nd edn., Erlbaum, Hillside, NJ.

De Milander, M., Coetzee, F.F. \& Venter, A., 2014, 'Developmental coordination disorder in grade 1 learners', African Journal for Physical, Health Education, Recreation and Dance 20(3:1), 1075-1085.

Department of Education, 2014a, Annual national assessment 2014, Department of Education, Pretoria.

Department of Education, 2014b, Curriculum and assessment policy statement 2014 Department of Education, North West.

Department of Education, 2014c, Education statistics in South Africa 2014, Department of Education, North West.

Department of Education, 2014d, Report on the annual national assessment of 2014 Department of Education, Pretoria.

De Waal, E., 2015, Die verband tussen ontwikkelingskoördinasieverstuering, akademiese prestasie en visueel-motoriese integrasie by leerders: Die NW-CHILD studie, MSc dissertation, NWU, Potchefstroom.

DeWan, L.K., 2006, Childhood development trends in executive function as measured by the Delis-Kaplan Executive Function System: An exploration of gender differences, PhD thesis, George Fox University, Newberg, OR.

Dewey, D., Kaplan, B.J., Crawford, S.J. \& Wilson, B.N., 2002, 'Developmental coordination disorder: Associated problems in attention, learning and psychosocial
adjustment', Human Movement Science 21, 905-918. https://doi.org/10.1016/ adjustment', Human Movem
S0167-9457(02)00163-X

Diamond, A., 2000, 'Close interrelation of motor development and cognitive development and of the cerebellum and prefrontal cortex', Child Development 71 , development and of the cerebellum and prefrontal

Driessen, G. \& Van Langen, A., 2013, 'Gender differences in primary and secondary education: Are girls really outperforming boys?', International Review of Education 59, 67-86. https://doi.org/10.1007/s11159-013-9352-6

Edginton, C.R., Chin, M., Amusa, L.O. \& Toriola, A.L., 2012, 'Health and physical education: A new global statement of consensus - Perspectives from South Africa', African Journal of Physical, Health Education, Recreation and Dance 18(2), A34-441.

Else-Quest, N.M., Hyde, J.S. \& Linn, M.C., 2010, 'Cross-national patterns of cross gender differences in mathematics: A meta-analysis', American Psychological Association 136(1), 103-127. https://doi.org/10.1037/a0018053

Frick, A. \& Möhring, W., 2016, 'A matter of balance: Motor control is related to children's spatial and proportional reasoning skills', Frontiers in Psychology 6(2049), 1-10. https://doi.org/10.3389/fpsyg.2015.02049

Gallahue, D.L., Ozmun, J.C. \& Goodway, J.D., 2012, Understanding motor development 7th edn., McGraw-Hill, New York.

Hanlon, H.W., Thatcher, R.W. \& Cline, M.J., 1999, 'Gender differences in the development of EEG coherence in normal children', Developmental Neuropsychology 16(3), 479-506. https://doi.org/10.1207/S15326942DN1603_27

Hartman, E., Houwen, S., Scherder, E.J.A. \& Visscher, C., 2010, ‘On the relationship between motor performance and executive functioning in children with intellectual abilities', Journal of Intellectual Disability Research 54, 468-477. https://doi.org/10.1111/j.1365-2788.2010.01284.x

Henderson, S.E., Sugden, D.A. \& Barnett, A.L., 2007, Movement assessment battery for children-2 (MABC-2), 2nd edn., The Psychological Corporation, London.

Korhonen, J. \& Linnanmäki, K., 2012, 'Language and mathematical performance: A comparison of lower secondary school students with different level of mathematical skills', Scandinavian Journal of Educational Research 56(3), 333-344. https://doi.org/10.1080/00313831.2011.599423 
Krinzinger, H., Wood, G. \& Willmes, K., 2012, 'What accounts for individual and gender differences in the multi-digit number processing of primary school children?', Zeitschrift zür Psychologie 220(2), 78-89. https://doi.org/10.1027/2151-2604/ Zeitschrift
a000099

Lax, I.D., Paniccia, M., Agnihotri, S., Reed, N., Garmaise, E., Azadbakhsh, M., et al., 2015, 'Developmental and gender influences on executive function following concussion in youth hockey players', Brain Injury 29(12), 1409-1419. https://doi. org/10.3109/02699052.2015.1043344

Lingam, R., Golding, J., Jongmans, M.J., Hunt, L.P., Ellis, M. \& Emond, A., 2010, 'The association between developmental coordination disorder and other developmental traits', Journal of the American Academy of Pediatrics 126(5), 1109-1118. https://doi.org/10.1542/peds.2009-2789

Lingam, R., Hunt, L., Goulding, J., Jongmans, M. \& Emond, A., 2009, 'Prevalence of developmental coordination disorder using the DSM-IV at 7 years of age: A UL population-based study', Journal of the American Academy of Pediatrics 123 693-699. https://doi.org/10.1542/peds.2008-1770

Lopes, L., Santos, R., Pereira, B. \& Lopes, V.P., 2013, 'Associations between gross motor coordination and academic achievement in elementary school children', Human Movement Science 32, 9-20. https://doi.org/10.1016/j.humov.2012.05.005

Luo, Z., Jose, P.E., Huntsinger, C.S. \& Pigott, T.D., 2007, 'Fine motor skills and mathematical achievement in East Asian American and European American kindergartners and first graders', British Journal of Developmental Psychology 25 595-614. https://doi.org/10.1348/026151007X185329

Melhuish, E.C., Sylva, K., Sammons, P., Siraj-Blatchford, I., Taggart, P., Phan, M.B. et al., 2008, 'Preschool influences on mathematical achievement', Science 321, 11611162. https://doi.org/10.1126/science.1158808

Michel, E., Roethlisberger, M., Neuenschwander, R. \& Roebers, C.M., 2011 'Development of cognitive skills in children with motor coordination impairments at 12-month follow-up', Child Neuropsychology 17(2), 151-172. https://doi.org/1 $0.1080 / 09297049.2010 .525501$

Mills, C.J., Ablard, K.E. \& Stumpf, H., 1993, 'Gender differences in academically young students' mathematical reasoning: Patterns across age and sub skills', Journal of Educational Psychology 85(2), 340-346. https://doi.org/10.1037/0022 0663.85.2.340

Missiuna, C., Rivard, L. \& Pollock, N., 2004, 'They're bright but can't write: Developmental coordination disorder in school aged children', Teaching Exceptional Children Plus 1(1), Article 3.

Nourbakhsh, P., 2006, 'Perceptual-motor abilities and their relationships with academic performance of fifth grade pupils in comparison with Oseretsky scale' Kinesiology 38(1), 41-48.

O’Brien, J.C., Williams, H.G., Bundy, A., Lyons, J. \& Mittal, A., 2008, 'Mechanisms that underlie coordination in children with developmental coordination
disorder', Journal of Motor Behaviour 40, 43-61. https://doi.org/10.3200/ disorder', Journa
JMBR.40.1.43-61

Pauw, K., 2005, 'Profile of the North West Province: Demographics, poverty, inequality and unemployment', Provided Project Background Paper 1(6), 1-9.

Piek, J.P, Baynam, G.B. \& Barrett, N.C., 2006, 'The relationship between fine and gross motor ability, self-perceptions and self-worth in children and adolescents', Huma Movement Science 25, 65-75. https://doi.org/10.1016/j.humov.2005.10.011

Piek, J.P., Dawson, L., Smith, L.M. \& Gasson, N., 2008, 'The role of early fine and gross motor development on later motor and cognitive ability', Human Movement Science 27, 668-681. https://doi.org/10.1016/j.humov.2007.11.002
Pienaar, A.E., Barhorst, R. \& Twisk, J.W.R., 2013, 'Relationships between academic performance, SES school type and perceptual motor skills in first grade South African learners: NW-CHILD study', Child: Care, Health and Development 40(3), 370-378. https://doi.org/10.1111/cch.12059

Pieters, S., Desoete, A., Van Waelvelde, H., Vanderswalmen, R. \& Roeyers, H., 2012 'Mathematical problems in children with developmental coordination disorder', Research in Developmental Disabilities 33, 1128-1135. https://doi.org/10.1016/j. ridd.2012.02.007

Pieters, S., Roeyers, H., Rosseel, Y., Van Waelvelde, H. \& Desoete, A., 2015, 'Identifying subtypes among children with developmental coordination disorder and mathematical learning disabilities, using a model-bases clustering', Journal of Learning Disabilities 48(1), 83-95. https://doi.org/10.1177/0022219413491288

Richardson, M., Hunt, T.E. \& Richardson, C., 2014, 'Children's construction task performance and spatial ability: Controlling task complexity and predicting mathematics performance', Perceptual and Motor Skills: Learning and Memory 119(3), 741-757. https://doi.org/10.2466/22.24.PMS.119c28z8

Robinson, N.M., Abbott, R.D., Berninger, V.W. \& Busse, J., 1996, 'The structure of abilities in math-precocious young children: Gender similarities and differences', Journal of Educational Psychology 88(1), 341-352. https://doi.org/10.1037/0022 0663.88.2.341

Roebers, C.M. \& Kauer, M., 2009, 'Motor and cognitive control in a normative sample of 7-year-olds', Developmental Science 12, 175-181. https://doi.org/10.1111/ j.1467-7687.2008.00755.x

Sadeghi, H., Abolghasemi, A. \& Hajloo, N., 2013, 'Comparison of cognitive failures and academic performance among students with and without developmental coordination disorder', International Journal of Psychology and Behavioral Research 2(2), 79-85.

Santos, P.A.P.D., Contreira, A.R., Caruzzo, N.M., Passos, P.C.B. \& Vieira, J.L.L., 2015 'Developmental coordination disorder: An analysis of nutritional status and socioeconomic level', Motricidade 11(1), 78-86.

Son, S.H. \& Meisels, S.J., 2006, 'The relationship of young children's motor skills to later reading and math achievement', Merill-Parmer Quarterly 52(4), 755-778. https://doi.org/10.1353/mpq.2006.0033

StatSoft, 2014, Statistica for Windows: General conventions \& statistics, Statsoft, Tilsa, OK.

Tsiotra, G.D., Flouris, A.D., Koutedakis, Y., Faught, B.E., Nevill, A.M., Lane, A.M. et al., 2006, 'A comparison of developmental coordination disorder prevalence rates in Canadian and Greek children', Journal of Adolescent Health 39(1), 125-127. https://doi.org/10.1016/j.jadohealth.2005.07.011

Van Lill, J., 2011, Jou kind kan wiskunde doen, Metz Press, Bellville, South Africa.

Voyer, D. \& Voyer, S.D., 2014, 'Gender differences in scholastic achievement: A metaanalysis', American Psychological Association 140(4), 1174-1204. https://doi. org/10.1037/a0036620

Vuijk, P.J., Hartman, E., Mombarg, R., Sherder, E. \& Visscher, C., 2011, 'Associations between academic and motor performance in a heterogeneous sample of children with learning disabilities', Hammil Institute on Disabilities 44(3), 276-282.

Westendorp, M., Hartman, E., Howen, S., Smit, J. \& Visscher, C., 2011, 'The relationship between gross motor skills and academic achievement in children with learning disabilities', Research in Developmental Disabilities 32, 2773-2779. https://doi. org/10.1016/j.ridd.2011.05.032 